\title{
Bill Clinton en Centroamérica
}

Las expectativas estaban ahí, a la espera de que los ofrecimientos providenciales del Ilamado "hombre más poderoso del mundo" las llenaran e hicieran de la región centroamericana un lugar más próspero y estable para sus pobladores. Ocuparon el primer lugar en los medios y en las cabezas de los presidentes del Istmo y de la más hermanada que nunca República Dominicana. Los discursos, las recepciones, los apresurados preparativos destinados a hacer la estadía del presidente de Estados Unidos, Bill Clinton, lo más segura y tranquila posible, tenían, de antemano, el sabor de quien agradece un favor ya anunciado y ansiosamente esperado. Pero, al final de la ardua jornada, nadie parecía estar conforme con lo recogido en el documento suscrito por los mandatarios en Antigua Guatemala. Los altos representantes de los igualmente altos sectores de la sociedad abandonaron la ciudad con más refunfuños que regalos.

¿Qué fue lo que salió mal en la Cumbre de presidentes de Antigua Guatemala? El evento culminaba con una apretada gira que Clinton realizó por los países más afectados de la región, tras el paso de la depresión tropical "Mitch", en noviembre del año pasado. Desde el principio, las promesas del mandatario estadounidense no se veían llegar con el empuje que se esperaba, o al menos, con el que los medios de información masiva -alimentados por las declaraciones de las autoridades gubernamentales - habían hecho esperar a sus públicos. No hacía falta ser demasiado perspicaz para adivinar el flojo desenlace al que este "histórico evento" llegaría, y, aun así, las reacciones han estado próximas a convertirse en verdaderas condenas del mismo. En este contexto, la pregunta arriba planteada no está de más: ¿qué ha hecho de esta Cumbre la que menos entusiasmo ha dejado sobre los que en ella estaban tan interesados?

Al parecer no bastó con poner en el tapete a una Centroamérica devastada y lista para recibir la ayuda internacional que, a manos llenas, le llegó en el peor momento de la crisis del "Mitch". Tampoco valió mucho haber presentado la problemática de los indocumentados como otro impedimento para el desarrollo de la región, esta vez oportunamente exagerado por el mismo fenómeno climatológico. Al final, en la Declaración de Antigua Guatemala, ninguno de los compromisos planteados parece ofrecer la varita mágica que aliviaría las heridas de los países que participaron de la reunión. En este sentido, se vuelve fundamental el análisis de los contenidos que se incluyeron dentro de la agenda preparada para la cumbre, así como también de las implicaciones que el reciente juicio político al que se enfrentó el mandatario de Estados Unidos pudieron haber contribuido al desenlace de la misma. Finalmente, y no menos importante, habría que hacer un balance de los compromisos planteados en la Declaración y las expectativas que, desde los intereses de los sectores más interesados en la cumbre, la rodearon.

\section{Una "super agenda" para la Cumbre}

En mayo del año pasado, el presidente de Estados Unidos, Bill Clinton, sostuvo una cumbre con sus homólogos de Centroamérica en medio de una difícil coyuntura para las relaciones entre estos países. Las constantes modificaciones a la política de inmigración de la nación norteamericana mantenían en vilo a los millones de indocumentados centroamericanos que radican en ella y las frágiles economías de la región se estremecían frente a la 
imposibilidad de asimilar esa pesada carga laboral. Este año, la historia se repitió con leves particularidades: en la última gira de Clinton por el área, los mismos temas ocuparon su lugar en las conversaciones, aunque esta vez estén mínimamente inclinados a favor de Centroamérica gracias al enorme peso que tuvo sobre la opinión pública internacional el paso de la depresión tropical "Mitch".

Durante los meses de enero y febrero pasados, los mandatarios de la región definieron conjuntamente los temas que abordarían en la cumbre presidencial. Cinco fueron los grandes puntos que se discutirían en la reunión de Antigua Guatemala. La política migratoria y la necesidad de concesiones en los lineamientos económicos que rigen las relaciones comerciales entre Centroamérica y Estados Unidos fueron los temas de los que más provecho se podía obtener, gracias a la devastación en que se hallaban algunos países de la región y Haití. La usual solicitud de inversión hacia la potencia mundial, como garantía para la estabilidad económica del área, también fue tomada en cuenta. La inclusión de otros tópicos relacionados con la transformación y reconstrucción de las naciones más afectadas por "Mitch" y el perdón de una parte de la deuda externa de la región con Estados Unidos aparecieron, igualmente, como puntos prioritarios.

Sobre las intensiones de las autoridades gubernamentales que participaron en la preparación de tan pesada agenda se puede decir bastante. Difícilmente se podría fundamentar su trabajo en la necesidad de recomponer la economía de la región, con el fin de buscar un crecimiento autosostenible. Además, esta posibilidad ha sido muy poco explorada por los gobiernos de los últimos años en la región, pese a la conciencia generalizada que existe acerca de las contradicciones y problemas que se derivan de los modelos de crecimiento económico que se implementan. Es un hecho que los efectos de los cambios climatológicos a nivel global, los desastres naturales y el corrosivo deterioro ambiental hacen de la región un lugar cada vez menos próspero no sólo para el comercio mundial, sino también para la vida de sus habitantes. Pero esta realidad no ha servido para impulsar un verdadero intento por implementar otro modelo de desarrollo, independiente del que dictan las potencias económicas, el cual raras veces contribuye a mejorar sensiblemente el estado de los países donde se aplican.

En virtud de esto, es necesario determinar dónde se hallaba el punto desde el cual era posible mesurar un verdadero avance con respecto a otras cumbres. ¿Qué actitud permitiría que los compromisos que se pretendían adquirir en esta oportunidad pudieran marcar un hito en el desarrollo de la región, en concordancia con los nuevos y viejos retos que a ésta se le presentan?

En principio, hay que descartar la pretensión de los presidentes centroamericanos de apegarse a una agenda común —aparentando una sólida unidad regional-, como un avance de dimensiones suficientes para hablar de una nueva era en las relaciones con Estados Unidos. Es más, los objetivos acordados no lograron superar la tendencia de algunos países de focalizar la atención en determinados puntos de la discusión por el provecho que, en particular, les suponían. Por ejemplo, Costa Rica sigue estando a la cabeza de los esfuerzos por conseguir mayores beneficios económicos para Centroamérica, mientras que del pastel del perdón de la deuda, Nicaragua y Honduras se llevarían el pedazo más grande. Por su parte, a El Salvador le convenía mucho más abogar por los indocumentados residentes en Estados Unidos y hasta se llegó a decir que no dio su apoyo para la posible condonación de la deuda. Ha sido esta actitud la que ha llevado al desmoronamiento de los flacos avances en términos de integración política en la región, tal y como ha ocurrido con las restricciones impuestas al $\mathrm{CA}-4$ por Guatemala.

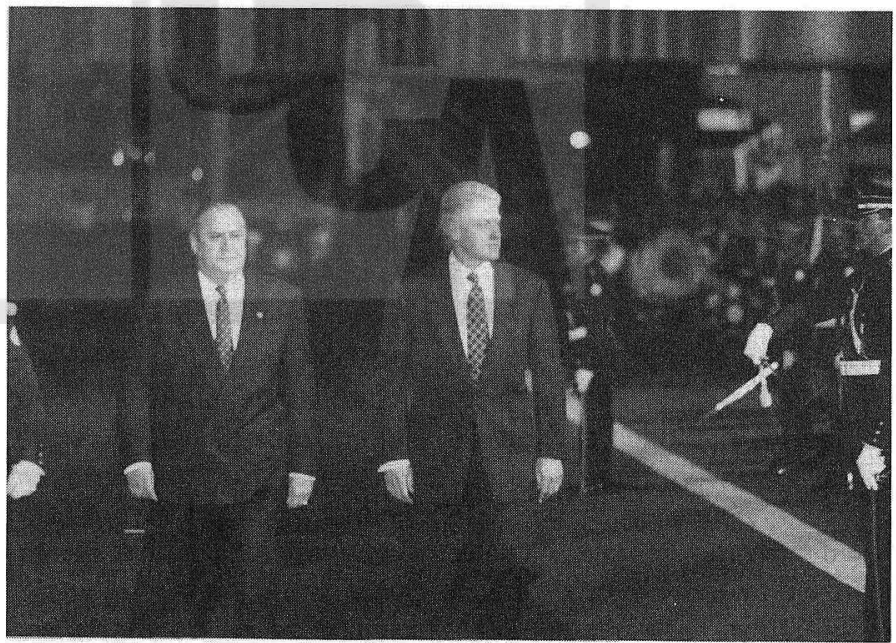


Pero aún más importante es observar que no se partió de una evaluación crítica de la política estadounidense de la última década hacia la región para fundamentar los objetivos de la cumbre. Si bien es cierto que la reconstrucción del área es un interés de dimensiones históricas, la "super agenda" de los presidentes no incluyó ningún punto que presionara directamente a Estados Unidos a reorientar su política de apertura de mercados hacia la región. Varios analistas coinciden en señalar que el empeño mostrado por Clinton en impulsar una política de comercio expansionista responde más al interés de las empresas transnacionales estadounidenses -quienes desde Wall Street financiaron buena parte de las campañas del mandatario-, que al desarrollo y bienestar de las economías de la región.

En la Declaración de Antigua Guatemala, por ejemplo, a los compromisos en materia de cooperación financiera y condonación de la deuda -donde se registró el principal aporte de Clinton a la exportación de productos textiles y de vestuario- le sigue la promesa de los presidentes del área de acelerar las discusiones para la formación del Área de Libre Comercio de las Américas (ALCA). Si el gobierno de Estados Unidos permite por ahora la implementación de medidas bilaterales en beneficio de unos cuantos países del continente, es un hecho que al terminar las discusiones para la creación del ALCA, la validez de esas medidas perderá, sin mucho reparo, su validez. El objeto de integrar a todo el continente en un proyecto de esta naturale$\mathrm{za}$, tiene como base el supuesto de que todos sus miembros se tendrán que adaptar a los mismos estatutos de intercambio comercial, y que las únicas concesiones que se permitirían tendrían que ver con los flacos compromisos de respeto de la identidad cultural y diferencias en los niveles de desarrollo que se firmaron el año pasado en Santiago de Chile.

Además, recordemos que Clinton ha protagonizado los más importantes esfuerzos de este siglo por consolidar acuerdos comerciales con países o bloques en toda América Latina; pero la cooperación en términos de pacificación, fortalecimiento de las instituciones estatales y modernización de los sistemas políticos de los países subdesarrollados ha quedado en manos de dependencias menores dentro del aparataje estatal estadounidense. $Y$ no es que los esfuerzos que dichas instituciones han realizado no tengan valor. Por ejemplo, la par- ticipación de la Agencia para el Desarrollo Internacional (AID) en el proceso de pacificación de Guatemala y en el desarrollo de programas de participación comunitaria en El Salvador y Nicaragua, representan un aporte positivo para ciertos sectores de la región.

Sin embargo, la atención que se ha puesto a este tipo de esfuerzos no ha sido capitalizada lo suficiente como para generar verdaderas transformaciones en la calidad de vida de la población, mucho menos en la forma como los gobiernos conducen a los países del área. En este sentido, si todavía son discutibles los alcances de los beneficios que la apertura de mercados pueda traer a Centroamérica, lo que salta a la vista por sí sólo es que, al plegarse sin mayor planificación a dichas estrategias, se corre el riesgo de acentuar viejos problemas (como la tendencia a fundar economías de especulación apoyadas en sectores financieros inexpertos, el debilitamiento de la industria y de la agricultura) o, en el peor de los casos, engendrar nuevos males.

\section{El juicio político de Clinton}

Por otra parte, hay que recordar que Clinton no ha estado en un lecho de rosas en los últimos meses. Los escándalos sexuales que han levantado polvo alrededor de su carrera política le han obligado a responder de forma decidida a problemas que su administración arrastraba desde hace bastante tiempo, en especial en materia de política exterior. Y, por cierto, en esas decisiones no ha primado precisamente una actitud respetuosa hacia la soberanía de los países que la potencia norteamericana tiene en la mira. La estabilidad y el apoyo que hizo retroceder a la jauría republicana que se apostó en torno a él durante el juicio Lewynski, le fueron concedidos porque alimentó el nacionalismo norteamericano por medio de la trillada demostración de fuerza propia del gendarme que defiende la seguridad nacional y - porqué no añadirlo- de todo el mundo.

Quizás lo fundamental que hay que extraer de la experiencia Lewinsky, para el caso que nos compete, tenga poca relación con el juicio político en sí mismo; más bien habría que atender al perfil que se estableció de Clinton frente a la crisis: a fin de cuentas, lo importante era mantener a flote la política demócrata que extiende sus raíces desde la Casa Blanca, y para ello se requería de un poder ejecutivo firme, con un ojo puesto en todo el planeta y el otro en los asuntos domésticos de la polí- 
tica norteamericana. Así, los misiles que Clinton lanzó hacia el oriente fueron la punta de lanza que desgarró su posible destitución. Y se debe reconocer que esta medida le funcionó bastante bien. Pero el hecho es que su carrera dentro de la presidencia todavía no ha terminado.

Ahora queda sobre sus hombros la misión de mantener a los demócratas en la presidencia de Estados Unidos y para ello deberá utilizar esa firmeza que le valió, en su momento, el visto bueno de un gran porcentaje de la población de ese país. Ceder en el tema de la inmigración, por ejemplo, habría significado ponerse en contra de la estabilidad de la mano de obra estadounidense que, a través del lente de los conservadores en el Congreso, ha visto en los inmigrantes una amenaza. Equiparar los beneficios comerciales de Centroamérica con los que goza México, en su calidad de miembro del NAFTA (Área de Libre Comercio de Norteamérica), daría muestras de flaqueza y arbitrariedad en un ritmo de expansión comercial que ha favorecido bastante a la potencia norteamericana. Desde esta perspectiva era muy poco probable que se dieran mayores avances en estos y otros temas durante la Cumbre.

\section{¿Sabor a derrota?}

Una vez iniciada la discusión formal de los temas de la agenda, los representantes de los gobiernos centroamericanos y de República Dominicana expresaban su absoluta confianza en que el mandatario estadounidense no dudaría en acelerar el ritmo y la calidad de la ayuda que su país les destinaba. Como si la mera publicidad de un evento con miras a tener éxito hubiera sido más importante que las posibilidades reales de que dicho éxito se produjera. En este punto, vale la pena considerar esa química entre lo deseable y lo posible que, al final de la Cumbre, opacó el carácter de los compromisos adquiridos en ella. Y es que la "super agenda" de los presidentes centroamericanos desde un principio expresaba el desenfreno de siete jefes de Estado que, tras haber recibido un apoyo sin precedentes por parte de la comunidad intemacional luego del "Mitch", se sentían con el derecho de recibir de Estados Unidos un trato condescendiente y generoso.

A la base de las discusiones que definieron los temas que le serían presentados a Clinton estaba, pues, la idea de que la política de dominación económica que Estados Unidos ha mantenido sobre la región podía cambiar drásticamente a causa de un desastre natural, que ni es el último ni el único de su clase ni representa en sí mismo la mayor preocupación de este país con respecto a Centroamérica.

$\mathrm{Y}$ en todo caso, como ya se ha dicho, esa agenda de temas ni siquiera destacaba la necesidad de que Estados Unidos redefiniera su papel en el desarrollo de los países del área, de manera que garantizara realmente el fortalecimiento de un modelo de desarrollo autosostenible. Aunque en algún momento este ideal hubiera pasado por la mente de los mandatarios, la base desde la que se levantó su gestión no era la más convincente para el presidente Clinton. Sus discursos tenían otro rumbo. Detrás de sus palabras estaba presente el deseo de que el flujo migratorio que existe desde el Istmo hacia su país se detuviera, o al menos, fuera más "controlado". Esa era su principal preocupación. Una vez logrado esto, se podía pensar en rebajar la presión que ejerce la política migratoria estadounidense sobre los indocumentados. Esa es la condición para que los países de la región empiecen un verdadero proceso de reactivación y crecimiento económico, según la lógica de Clinton.

De hecho, en los compromisos referentes a política migratoria suscritos en la Declaración de Antigua, mientras Estados Unidos sólo se compromete a "atender las disparidades creadas por la Ley de Ajuste Nicaragüense y Desagravio Centroamericano (NACARA)", a los gobiernos del Istmo, de Belice y de República Dominicana les compete: garantizar migraciones ordenadas hacia Estados Unidos, así como controlar el flujo migratorio desordenado que hasta la fecha existe, ofrecer más y mejores oportunidades de empleo a los habitantes de los países de la región, facilitar la reinserción de los deportados, además de proporcionar un tratamiento adecuado a aquellos que tengan antecedentes penales, y combatir el tráfico ilícito y organizado de personas hacia la potencia norteamericana.

En conclusión, podemos afirmar que la Cumbre de Antigua Guatemala no falló a causa de lo poco que el mandatario estadounidense trajo, sino más bien (y en parte) porque las alforjas dispuestas para recibir sus concesiones eran demasiado grandes. A esto podríamos añadir la poca disposición de intercambiar compromisos con el mandatario que ha demostrado la clase empresarial frente a las condiciones impuestas por Clinton en sus discursos. Ha sido la misma voracidad de la clase 
empresarial centroamericana la que contribuyó a imprimir a este cónclave el sabor de derrota que tuvo. Los sectores económicamente poderosos de la región vieron en este evento la oportunidad de obtener las condiciones más propicias para elevar sus ganancias. Por lo tanto, los compromisos adquiridos, que más bien apuntan hacia una recomposición de la producción interna de cada país, no encajaron del todo con lo esperado por estos sectores, para quienes el desarrollo no es más que una garantía de su exclusiva estabilidad económica.

\section{Consideraciones finales}

En el discurso The State of the Union de 1998, Clinton insistía en la responsabilidad de su país frente a la seguridad y estabilidad del mundo entero frente al nuevo milenio. Pero el hecho es que esa seguridad y estabilidad a las que el presidente hizo referencia al filo de su enjuiciamiento, no tienen mucha resonancia en la situación que se vive en el Istmo. No la tendrá mientras no dé muestras de verdadero interés por apoyar a sectores políticos y económicos, cuyo trabajo en verdad contribuiría a fomentar el desarrollo de la región. Tampoco si mantiene posturas ambiguas ante la xenofobia de los conservadores republicanos en el congreso, a sabiendas de que lo que ha caracterizado su gobierno es la capacidad de amoldarse a las intempestivas crisis que aparecen en el camino. Mucho menos si no define un papel verdaderamente protagónico en la protección del medio ambiente, en el combate a la utilización de Centroamérica como puente y resumidero de drogas y en el estudio y control de la violencia.

No se trata de pensar en Estados Unidos como la panacea de todos los males de la región centroamericana, pero no cabe duda de que ese país tiene el poder suficiente para influir en la puesta en marcha de soluciones radicales y efectivas en contra de aquéllos. Se trata simplemente de asumir la responsabilidad que Estados Unidos ha adquirido históricamente con respecto al ritmo de desarrollo de los países latinoamericanos. Claro está que la realización de un ideal de verdadera cooperación mutua supone el abandono de todo tipo de estrategias, para mantener un dominio hegemónico sobre las economías de los países del istmo. Sin embargo, el gobierno de Clinton parece estar lejos de prescindir de tales objetivos. Los presidentes de la región deberían tomar nota de esto para, finalmente, marcar la diferencia con respecto a otras reuniones y ofrecer verdaderas oportunidades a sus pueblos para el nuevo siglo.

El mensaje de Clinton fue claro y ha sido reconocido por los presidentes de la región: debemos erradicar las causas que hacen que miles de compatriotas salgan de sus países para procurar una mejora en sus condiciones de vida, esto es, la pobreza. Pero este mensaje (tal vez el de mayor relevancia de todo el discurso del mandatario) será muy poco aprovechado si no se reconoce antes que la Cumbre nació moribunda desde el momento en que los gobiemos plantearon sus contenidos. En consecuencia, a la decepción de los sectores empresariales y de los gobernantes mismos no le debe seguir la resignación, sino la reflexión acerca de lo que en verdad se desea para los países de la región y del papel que se espera que asuman las naciones que cooperan con la reconstrucción y transformación del área. Esta actitud implica replantearse la concepción de desarrollo que se expresa cada vez que hay oportunidad de estrechar lazos comerciales con otras naciones, de manera que ese desarrollo sea equitativo y palpable para cada uno de los habitantes del Istmo.

Cristopher Estrada 